\title{
الشهود الفكري مقدمة للشهود الحضاري
}

قراءة في كتاب: الشهود الحضاري للأمة المسلمة

$$
\text { المؤلف: الدكتور عبد المجيد عمر النجار }
$$

دار الغرب الإسلامي، بيروت 1999 ثلاثة أجزاء مجموعة صفحاها ما يقارب 800 صفحة.

\section{* محمد بن حامد الأممري}

لا يمكن أن نكتفي بهذا المقال الصغير إن أردنا أن نقف مع المفكر المجيد الدكتور عبد المجيد بن عمر النجار في

حوار وقبول ورد لما أورده في كتابه الكبير المهم: "الشهود الحضاري للأمة الإسلامية". لأنه جال ميادين متعددة في الفكر والتاريخ والعقائد وفلسفة النهوض، ووضع خلاصات منها ما يستحق المراجعة والنقاش، وأكثرها مما هو جدير بالإشادة والنشر.ولا شك في أن قارئاً صبوراً سوف يستمتع هذه الأسفار الثلاثة؛ غير أن الحجم وبقايا من أسلوب الكلاميين القدماء، وفلاسفة الحضارة المعاصرين يبقى من عوائق الاستفادة من هذا البحث الشمولي كما يليق به. وليس لنا إلا الوقوف على قضايا سريعة في الكتاب تتناسب مع مقال مجمل عنه، غالبه نقاط للحوار حول بعض موضوعات الكتاب وقضاياه، وملاحظاتنا هنا لا تنقص من قدر الكتاب وأهميته.

قضية الكتاب:

أشار المؤلف إلى أن المعهد العالمي للفكر الإسلامي عهد إليه أن يكتب "دراسة عن حركات النهضة الإسلامية

التي قامت منذ قرنين ونصف من الزمن هادفاً إلى إصلاح أمر الأمة؛ لتتحرر من تخلفها؛ وتستعيد شهودها الحضاري، ولكنها لم تتوقف في بلوغ ذلك الهدف، فلماذا لم تبلغ الحركات أهدافها، فبقيت المطالب التي قامت من أجلها قائمة جيلاً بعد جيل؟1 "ولكن المؤلف كتب قرابة خمسمائة صفحة مقدمة للدراسة المطلوبة حول فلسفة النهوض، أو سماه

$$
\text { 1 } \quad \text { ر بيس أمناء التجمع الإسلامي لأمريكا الشمالية. }
$$


في الجزء الأول فقه التحضر الإسلامي، والجزء الثاني :عوامل التحضر الإسلامي، والجزء الثالث: مشاريع الإشهاد الحضاري، وهي الدراسة المطلوبة في بادئ الأمر. وقد كان الجزءان الأول والثاني غنيين بالبحث والمدارسة ومحاولة الاستبصار في الفكر العالمي في جزئه الأول، ثم محاولة متميزة في الجزء الثاني بما تلخصه العناوين ب: كشف العوائق، رشاد الاعتقاد، سداد الفكر، النفير الحضاري، سلطان الإنجاز.

والكتاب متأثر بالتأصيل الإسلامي الشرعي، ناع على المدارس التي أغفلته، محتفل بالعلماء الذين كان لهم دور في المشاريع، كما أنه في تنظيره في الجزء الثاني ظهر أيضاً متأثراً بالتوجهات الغربية في بناء المجتمع وصياغة علاقاته، ولاسيما في الجزء الأخير من المجلد الثاني. وقد ساعدته كثيراً فلسفته التي سطرت بوضوح في الجزء الثاني أن يلاحق الجماعات والأحزاب والمشاريع بملاحظات قيمة، مسترعياً الانتباه لمواضع النقص. وإن كان هذا الجزء محتاجاً لأن يكون أصغر مما ظهر به.

إن تماسك القضايا الفكرية والمنهجية والعقدية والتاريخية جعل المؤلف يضطر إلى دخول ميادين واسعة من المراجعة والنظر. فكانت مسائل كالسننية وفلسفة التاريخ وقيام الحضارات وسقوطها، ومشكلات الفكر العملي أو المجرد أو الموروث أموراً لم يستطع الكاتب أن يذهب لمراده قبل أن يقف عليها وقوفاً طويلاً لم يمكنه وقوفه هذا من أن يستقصي البحث فيها، ولم يوجز غايته منها. فأبقى في كل زاوية فراغاً أو سؤالاً يلح بإجابة. والتحدي واجه المؤلف بسبب طموح كبير للاستيعاب صعب البلوغ ومشروع محدد لا بد له من إنجازه.

فالقضايا التي حاول أن يجيب عليها في مقدماته وملاحظاته هي نفسها عمل المشاريع الإصلاحية الإسلامية جملة. ومسألة منها واحدة كانت مشروعاً لأشخاص مثل مالك بن نبي، أو إقبال أو جمع ممن عرض لهم، وهو لا يكتفي بالعرض والنقد، ولكنه يقول الحلول بطريقة التعليق أو النقد في طريقه إلى نقد المشروعات الإسلامية.

يمر الكتاب بمراحل متنوعة من الإجادة والأفكار العميقة، وقد وفق في معظم مناقشاته، ثم يضعف النص أحياناً ويكرر في السياق أقوالاً سبقه هما غيره من دون وعي نقدي بها. أو أنه يستسلم لثقافته السابقة أو مسلمات ماضية وقد يكون مطلباً صعباً أن يفترض في كاتب أن يقنع قارئه دائماً، أو أن يحوز على إعجاب قارئه الجديد. كما أن الكتاب في حجمه هذا لم يخل من تكرار للفكرة تساق بوجوه متعددة. 


\section{مشكلة التحقيب والتصنيف والتسمية:}

يحتاج مؤرخ الفكر أن يجقب ويصنف فكرياً أو زمنياً، ليسهل عليه معالجة العدد الهائل من المدارس والأفكار، فيبني حجرات فكرية يجمع في كل واحدة من يراهم متقاربين في التوجه أو الزمان أو المكان، يفصلهم عن غيرهم ويدرسهم ويحقق في التشابه فيما بينهم ويبين مفارقتهم لمن عداهم، وبدون هذه الفصول والتحقيبات لا يستطيع الدارس أن يتبين معالم هذه المدارس. ولا أن يدلك على التقسيمات الفكرية في هذه المجتمعات.

وقد قسم الكاتب التوجهات الإسلامية إلى ثلاثة أقسام اعتسفها اعتسافاً دون تحقيق للفكرة: فالسلفية والتحررية والإيمانية إنما كانت تقسيمات معتسفة أثر فيها العامل التاريخي في البدء أكثر من العامل الفكري الذي وضعه عنواناً، ثم اضطره هذا التقسيم أن يعتسف الأفكار والحقائق التاريخية والجغرافية لتنسجم مع تصنيف لا دليل عليه. لقد قسم الكاتب مشاريع الإشهاد الحضاري ومؤسسيها إلى ثلاث مدارس:

\section{المشروع السلفي: الوهابية، والسنوسية والمهدية}

المشروع التحرري الطهطاوي، السير أحمد خان، خير الدين التونسي، الأفغاني، محمد عبده، الكواكبي، ابن باديس. ثم ابن عاشور الذي يأي ذكره في سياق الحكم المحقق فوق المدارس والمذاهب. مشروع الإحياء الإيماني الشامل: الإخوان المسلمون، والجماعة الإسلامية في الباكستان. والاعتراض على تقسيمه من وجوه:

أولاً: المؤلف محتاج تاريخياً للبدء بالسلفية محمد بن عبد الوهاب والمهدي والسنوسي، ولكن هل السلفية هي نفسها الجامع بين الوهابين وبين المهاي في السودان؟ وهل شعار الكتاب والسنة الذي رفعه جل المدارس الإسلامية يكفي جامعاً مانعاً في التعريف؟ ثم يفهم من التحررية أن السلفية ليس فيها لموضوع التحرر مجال، أو هو أضعف من غيره، ولم يكن لها صلة بالغرب، فماذا تقول عن المهدية وموقفها من بريطانيا وقتل جوردون؟ أم كيف يكون محمد 
عبده تحررياً مع ما أشار له الكاتب من علاقته بكرومر2 وما هو أكثر من مهادنة الغرب؟ وكيف يمكن لابن باديس أن يقرن مع سير أحمد خان في قرن؟ وخان المتغرب كما يشير المؤلف لا يكاد يجمعه جامع مع جبهة الإنقاذ التطور الطبيعي لسلفية ابن باديس ووهابيته، ويمكن لأي موال وفيّ لبريطانيا متحرر من الدين أن يكون مثثلاً لسير أحمد خان. وإذا كان الكاتب يريد وضع أو تحقيب حقبة علمانية داخل البحث أو مستبعدة منه، فلم لم يدخل خان لهذه المدرسة، أو الكواكبي أو قاسم أمين؟

ثانياً: ما الذي أوقف السلفية عند هؤلاء الثلاثة؟ وما الذي أوقف التحرية هناك بلا امتداد؟ فكأن السلفية والتحررية لم توجد في من بعدهم، ولم القطيعة التي أصر عليها الكاتب بين هذه المدارس؟ فسلفية جبهة الإنقاذ ظاهرة الجذور الفكرية، وسلفية رشيد رضا معلومة، والبنا والمودودي ما الذي يجعلهم في دائرة إيمانية واحدة ويقطعم عن غيرهم؟ ألم يكن التحرر هاجس المودودي؟ والسلفية داخل المعسكر الإيماني مما لا يحتج لدليل. والتحررية فمشروع محمدابن عبد الوهاب ورشيد رضا والإخوان أقرب للتوجه السلفي، ومشروع المودودي أقرب للمشروع التحرري، ومشروع السنوسية أو الكمهدية هي أيضاً مشاريع تحرية باعتبار التحرر من الاستعمار. ومشروع المهدي ومحمد بن عبد الوهاب فيه نزعة تحرية تناسب زماغم. إنما المفهوم الليبرالي عند الطهطاوي وغيره كان مشروع التحرر من الدين. وما النصوص التي نقلها المؤلف عن إعجاب الطهطاوي بالرقص الفرنسي، ثم حياته إنما هي مثال للتحرر من الدين وليس من الغرب. ووصف مشروع الإخوان والجماعة الإسلامية بالمشروع الإيماني يجرده من الألقاب التي وصف بها الآخرين أو على الأقل يميزه عنهم، وقد كان الخطاب السياسي والإيماني حاضراً في المشروع الإخواني منذ البداية، بقطع النظر عن النتائج. وقد أشار لإعجابه الكبير بمشروعين هما مشروع البنا ومشروع السنوسي.

ثالثاً: التحرر من الخزافة ومن الاستعمار كان سمة بارزة في السلفية منه في من سماهم بالتحرية، فعبده وخان والطهطاوي، أي مكان لهم من مسألة التحرر السياسي؟ وخان بريطاني الهوى وضد دعاة الاستقلال وعبده وعلاقاته وموقفه من عرابي -كما في مذكرات محمد عبده نفسه- لايجعله لائقاً هذا التصنيف. وقد تضافرت على الكاتب مشكلات التصنيف والتأريخ والتسمية فهذه التسميات الثلاث جعلته يجمع بين المتناقضات. فتحرير التسميات سوف يجعله قادراً على تبين الخلاف الكبير بين المدارس.

راجع هذا الموضوع كتاب محمد محمد حسين الإسلام والحضارة الغربية. وهو من أشد المعارضين لفكر عبده والأفغاني. ولكن أمر علاقته بكرومر جاء في التقارير التي كان يرفعها كرومر للحكومته. 
أزمة المذهبية:

إن متابعة الكتابابت التي ظهرت قديماً حول كتاب المؤلف عن المهدي بن تومرت-لعلها رسالته للدكتوراهوموقفه من تلك المناقشات بتعل القارئ لا يشك قبل قراءة الكتاب أن المؤلف سوف يكون له موقف متحفظ على السلفية، لأسباب عقدية تاريخية، ولأسباب معاصرة خارجة عن موضوع البحث. ولأسف لم يستطع الخلاص من هذا الإرث، فقد حاول -مشكوراً - في بعض الومضات. غير أنه لم يتعامل مع مصادره بطريقة واحدة، فمرة يكتب من المصادر ومرة من المراجع، ولم يحافظ على منهجية فيها، ولا عيب أحياناً ما لم يكن ذلك في بعض القضايا التي تحتاج لدقة أو هي موضع خلاف. فالمدارس الموالية يكتب عنها من مصادرها أو من مصادر المعجبين بها، والخصوم يكتب عنهم من كتب خصومهم، وهذا لا ينتج نصاً محايداً في النهاية وإن حَرَصَ الكاتبُ.

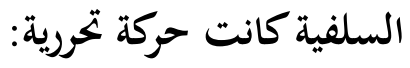

لم يقف الكاتب عند دور أو أثر الحركة السلفية في التحرر من الاستعمار، وكان اللائق به أن يربط الحركة

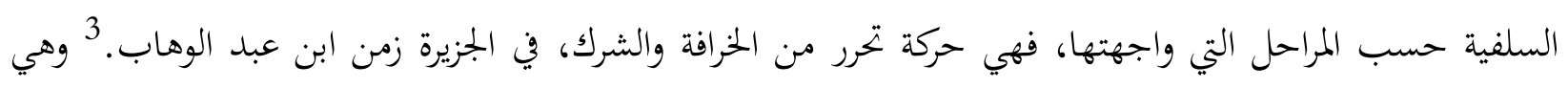
حركة تحرر العقل، وقد وجد زعماء الحركة العقلانية أنفسهم يدافعون عنها ضد التصوف والرضوخ للعثمانيي، من أمثال محمد عبده، وتلميذه الطاهر بن عاشور. ثم قامت على أثر ذلك حركة تحرية من الاستعمار في شثمال إفريقية فحضورها في فكر ابن باديس والإبراهيمي وهيئة العلماء الجزائرية، ثم حركة السلفية الوطنية المغربية في الريف المغربي

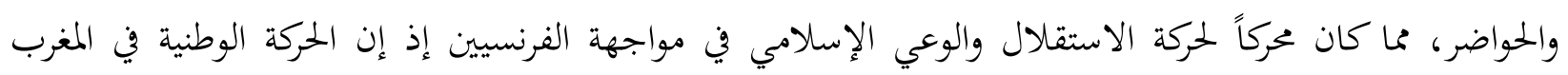
العربي الكبير ولاسيما الجزائر والمغرب كانت تحالف السلفية مع القوى الوطنية، على حين تحالفت أكثر الفرق الصوفية مع المستعمرين ولاسيما في المراحل الأخيرة من المواجهة مع الغرب. ولو رجع الكاتب إلى كتابات بعض العلمانيين 
والوطنيين ممن أثرت فيهم وصاغت مواقفهم الحركة السلفية، بل وأرخوا لها لكان أليق في هذا السياق، من أمثال محمد عابد الجابري الذي أرخ لهذا في كتابين أحدهما مذكراته.

نعم إن التقسيم الفني للبحث قد يدعو الباحث إلى تقطيع الحركة إلى وحدات بحثية موضوعية أو زمنية، واضحة ويتجاهل بعض التداخل، ولكن ليس إلى هذه الدرجة من الفصل التي أتت على عناصر مهمة من تركيب الحركة السلفية ودورها في اليقظة. فقد أثر الزمن على الفكرة وليس العكس.

أو يبدو أن عوامل تاريخية أو إقليمية عدت على مؤرخي الفكر الإسلامي من الإسلاميين جعلتهم، يقزمون الحركة السلفية جهدهم، حتى وجدت في القوميين العرب إنصافاً لم بتحده عند أهلها الإسلاميين. وهذا واضح بشكل أكبر عند بعض أدبيات حزب التحرير الإسلامي، مثل سقوط الحنلافة لزوم، الذي يحمل محمد بن عبد الوهاب وزر إسقاط الخلافة. وما المسافة التي يمكن وضعها بين سلفية رشيد رضا والبنا؟ ألم يكن لمحمد عبده أثر في توجيه رشيد نهو سلفية أكبر؟ لا أستبعد أن الجذور العقلانية وجدت لها مكاناً عند رشيدفي السلفية، ولم يكن عبده قادراً على ملء الفراغ عند تلميذه. إن المتغيرات الزمنية التي أحاطت بالسلفية المعاصرة ما كان لها أن تساهم في إلغاء ماضي اليقظة الفكرية والقومية "فيما يرى القوميون" وقد أخطأوا التحليل واعتسفوا الحركة لتكون قومية الهدف في مواجهة

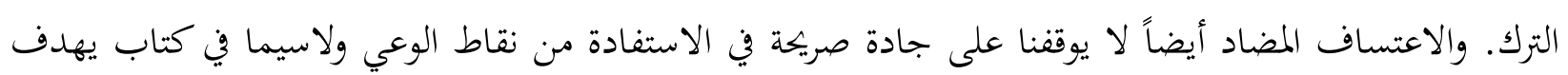
بشكل كبير لالتقاط نقاط القوة والبناء وتوظيفها مرة أخرى.

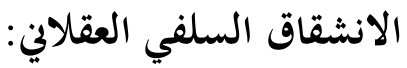

هل الحركة العقلانية التي سماها التحرية، تمثل انشقاقاً داخل الحركة السلفية؟ أم رداً عليها؟ أم أن السلفية هي الحركة الأم التي ولدت أحزاباً وجماعات بعضهم خالفوها في المصير؟ قد يكون من المناسب استصحاب مجمل الآراء التي سيقت في المسألة حتى من كتاب العقلانية المتجاوزين لموقف النجار من أمثال محمد فتحي عثمان في كتابه السلفية وغيره. ففي الخط التحرري خط سلفي لا يقل أثره عن المجموعة التي أصبحت تسمى ليبرالية اليوم. فموقف 
محمد رشيد رضا لا يجد مكانه في تصنيف المؤلف، إما لسلفيته وإما لجموده كما يقول. فهو -بعد وفاة شيخهشخصية ذات مرجعية تأصيلية مختلفة، وبقيت العلاقة تاريخية لا مدرسية.

\section{قيود المذاهب والجغرافيا:}

كم يطمح القارئ المسلم أن يقف على فكر بتديدي إسلامي حر من أغلال المذهب أو الجغرافيا أو الصراع الذي أبقاه الماضون -هي عصور الضعف الإسلامي -إرثاً يتحكم في عقول اللاحقين، وأملت أن أجد في كتاب يؤسس لمشروع شهود حضاري تغلباً على هذا الضعف والنقص الملازم للتفكير الإسلامي المذهبي أو الإقليمي، ولكن للأسف لم يتخلص منه كاتبنا الجاد، بل يصلح كتابه في عدد من المواضيع أن يكون مثالاً للخضوع للتقليد وللتاريخ والمذهبية التي تضحي بالرؤية الصحيحة من أجل ما لا يستحق.

فإن قارئاً يبحث عن استراتيجية للشهود الحضاري لا يستطيع أن يفيد كثيراً من كتاب يممل خصومة عفا عليها الزمن، ويخفض من الأفكار الأخرى؛ لأها ولدت في غير إقليم المؤلف، أو خرجت من غير مذهبه، مهما كان لها من قوة التأثير ونفع الأمة الشامل، ويعامل أفكاراً لها شفيع من قرب إقليمي أو نسب فكري عكس ذلك.

نجد أنه يرجع في تقويم الوهابية إلى كتابات الخصوم مثل محمد عمارة الوارث الثالث للنقد، ويرجع في كتابات السنوسية والمهاية إلى كتابات الأصدقاء والمعجبين مثل شكيب أرسلان وأبي سليم. لقد كان مناسباً للمؤلف كما وقف على الرأي في السنوسية من خلال رجل عاصر السنوسيين وخالطهم وصادقهم، أن يقف على نفس النمط من العلاقة مع البقية فكان بإمكانه أن يستند لابن بشر، أو للجبرتي مراقباً بعيداً للحدث أو لغيرهم. بل لرأي مثل رأي محمد عبده والطاهر بن عاشور في الحركة السلفية.

أما النقد الذي يلاحظه على الوهابية وقد أصاب في كثير منه، فهو ينصرف إلى مرحلة لاحقة بعد أن أصبح للوهابيين دولة، ولكنْ لماذا سكت عن دولة السنوسية إلى إدريس السنوسي الذي قضى القذافي على حكمه؟ ولماذا سكت عن المهدية إلى يوم الصادق المهدي هذا؟ وإن كنت أفضل له أن يفصل الدعوة عن الذين ورثوها في الحركات 
الثلاث، وهنا يستقيم له منهج نقدي متماسك. وسوف يجد نفسه قادراً على النقد للحركة الوهابية أكثر من غيرها،

لا يحير الكاتب جواباً. والجواب أن الوهابية حركة ضخمة، بتح فيها ما تتفق معه وما تختلف معه، وتوفر لها من

الكتاب والمؤلفات والأعمال ما يستحق الذكر مدحاً أو قدحاً، وكانت الحركة السنوسية إحدى أبعادها، وذلك ما يسكت عنه الكاتب بلا سبب. ثم حركة التحرر السلفي التي كان آخر قادتا ابن باديس، ورواد التحرر في المغرب الأقصى كانوا من الحركة السلفية تلك التي أنضج تصورها ابن باديس والإبراهيمي في أثناء طلبهم للعلم في المدينة المنورة كما يشير الإبراهيمي في مذكراته.

\section{المبالغة في نصر الفكرة: - 20 - 20}

في لحظات النهوض الحضاري، ولحظات اليقظة يحب كاتبنا، بل كتاب التحقيب الفكري، والتاريخي غالباً أن يبالغوا في رسم القواطع بين العصور، والشخصيات والأمم، ثم تبلغ المبالغة بهم أن يسحبوها على غير بجالها. فالكاتب يعجب بعمر بن الخطاب رضي الله عنه. والطاقة العجيبة التي فجرها الإسلام في كيانه فيقول: "فإذا

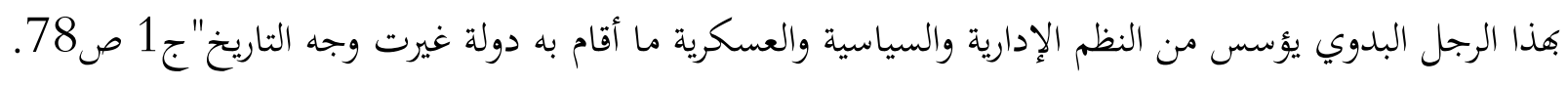
وكما ترى فإن الوصف لا شك في خطئه وإلا فلا معنى لكلمات المدينة والقرية ولا معنى لكلمة حضارة لو شئنا نقلها للماضي أو للغة، إن كان عمر "بدوياً". ومجتمع الجزيرة وقت الرسالة كغيره آنذاك وكمعظم بلدان العالم عبر العصور، وينقسم إلى حواضر مدنية، وإلى قرى أقل تمدناً وإلى بداوة، فإذا كانت مكة هي البداوة فأين القرى العربية الصغيرة؟ وأين معنى التعرب والبداوة الذي نسمي أهله بالبدو؟ وتسميهم كتب التراث أجمعها "أعراباً" إلا أن تكون الحضارة لها معنى غير المعنى العربي المعروف الذي ذكره القطامي بقوله:

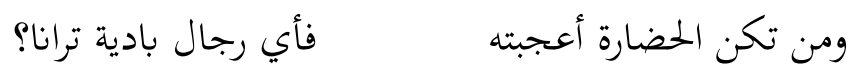


أو أها تعني مراحل الاستقرار المدني في لحظات غروب الحضارات الفارسية والرومية! إن الكاتب يرمي ببعض الكلمات التي لعله لا يقصد ظلالها.

فالبداوة والهجمات البدوية في التاريخ مدمرة للحضارات، يستوي في ذلك بادية الهكسوس، وبادية العرب، وقصة المغول والهجمات البربرية الجرمانية على حواضر أوربا، وهي اللحظات البدوية التاريخية، وهي مرحلة ما قبل الحضارة، وهي المرحلة المقابلة لما بعد الحضارة. وكلا اللحظتين من اللحظات الميتة في تاريخ البشرية يغلب على أولاهما الجهل والعجز والتوحش، ويستحيل أن تنجب مثل عمر، ويغلب على الثانية موت الأفكار، وتفسخ المفاهيم وبتزئة الحياة وتمزق الفرد وخنوعه لمرحلة الكماليات التي ذهبت، أو ذكرى متعها المادية أو الروحية والتاريخية. وفي هذه المرحلة يستسلم المجتمع لغزو خارجي متوحش بدوي يزيد من ليله الكئب، أو يرزق بمدنية غازية جديدة هادية كالإسلام أو مستغلة اقتصادياً وعسكرياً كما شهدنا في الغزو الغربي لحضارتنا الإسلامية، أو لغيرها من الحضارات التي سقطت أو ذهبت من التاريخ هائياً كالحضارات السابقة للاستكشافات في العالم الجديد.

\section{خيارات التحقيق بين الأدلجة والتفلسف:}

الكتاب يقع في أزمة الفصل بين الدراسة العلمية المدعومة بالأدلة وبين التوجه الإيديولوجي التحميسي للإقناع بفكرة. فالأولى قد يغلب عليها البرود العاطفي، والتعقل المنطقي، والأخرى يغلب عليها الهدف المطلوب تحقيقه أولاً بقطع النظر عن حضور المبالغات العاطفية، ورغبة الكاتب في تأييد فكرة محددة. إن بحثنا كهذا نرتقب منه أن يتخلص من عقدة التفكير الإسلامي المتحمس الذي يلغي المؤهات المدنية لمكة والمدينة والجزيرة العربية قبل الإسلام، لتكون قد جاءت الدعوة من وحي فقط بلا بجتمع زاخر بالمشكلات، أو بجتمع يلذ للصوي تصويره بالفقر والجهل وموت الفكرة، أو يقيم الأحداث على فلسفة قومية نبتت بعد أكثر من ألف عام. ويعرض عن العوامل الدينية إن كان ماركسياً، أو يبالغ في رسملة بجتمع مكة إن كان يسارياً. ويجعل الحدث كله وبملابساته المعقدة مجرد حدث غيبي فقط، لا علاقة له بإمكانات البشر المادية التي ساهمت في تحقيق مقاصد النبوة، وهذا التفسير هو رد فعل للتفسير الماركسي والتفسير القومي، وغير مبني على سننية قرآنية صحيحة.

إن الله عز وجل اختار بجتمعاً بلغت فيه الصفات والعلاقات البشرية أرقاها بمقاييس ذلك العصر، لم يكن بجتمعاً بدائياً عاجزاً عن استيعاب الثقافة وأعلى مراتبها النص القرآني، ولم يفسد في مدارج المدنية والاستبداد أو 
الرخاوة ما بعد الحضرية، ولم يكن ميتاً بتحاه القوى المستبدة، وإلا فكيف نقرأ معركة ذي قار وغيرها؟ وهروباً من التفسير القومي أيضاً تلغى عوامل اجتماعية وقبلية ولخظات تاريخية متعددة ومهمة. يقابل ذلك التفسير الذي يغرق في رسم رأسمالية بجتمع مكة، ويفسر الدعوة الإسلامية تفسيراً طبقياً ضد طبقتها المتنفذة ويضع الدعوة في خندق البروليتاريا.

وإن الحركات الرئيسية الثلاث التي سماها بالسلفية نشأت في مجتمعات شبه مدنية، بل أقل من بجتمع الدعوة الأولى مدنياً فالدرعية وشرق ليبيا أو واحة الجغبوب ومهجر المهدي ما هي إلا مناطق كفلت لها العزلة بعض النجاح، بل هرب السنوسي قصداً من التماس مع تركيا ومع بوادر الخوف من الغرب إلى الصحراء حيث يككنه بناء مجتمع السنوسية.

ولم يعط الباحث الفاضل نصيباً كافياً للمسألة السياسية في الحركات السلفية والإممانية، بالقدر الذي يتناسب وحجم مشكلة هذه المدارس مع السياسة، ربما بحنباً للتعقيد أو مراعاة للواقع، ولكن هذا يبقي علاجه لموضوع السياسة والدعوة لهذه الأعمال في دائرة ألح الكاتب كثيراً على التحذير منها وهي الإجمال والجزئية والسطحية.

وقد آن لنا بعد سقوط أو تدهور المدرستين "القومية واليسارية" أن نعيد التوازن لقراءة تاريخنا، مستعينين بشواهدنا، وإن لم نكن بعد قادرين على وضع نظرية خاصة، فالدراسة الواعية المستقلة أول الدرجات في بناء فلسفة تاريخية بديلة.وقراءة السنن الإلهية في جميع المواقع، مع تجرد مقصود من ثقل الفلسفات التفسيرية التي تحاصرنا خير لنا. وأن يقف عالم أو دارس يسوق حقائقه دون قسر لها على تفسير لهو خير له ولمن قبله ومن بعده من التمذهب الذي يودي بالدراسة وبهدفها، ويلحقها بفرع فلسفة ضخمة قاسرة، خدعت الناس بضخامتها ذات يوم أو بقدرتا على توهم حل الإشكالية. أو حل صحيح ولكنه يصدق على حدث أو زمن أو بلد ولا يصلح تعميمه.

وبهذا يستطيع التأدجا والتحمس اللذان شكلا قطاعاً كبيراً من مواقفنا الفكرية أن يشلا قدرة الدارس عن تبين الحقائق.على فرض أن الحقيقة هدفه.

إن التبين وكشف العلة عمل أصبح من المهم أن يتم بتجرد كبير، ومحاولة الإنقاذ ورسم المستقبل لا يسمح أيضاً بالتجاوزات، وبعض المغالطات في كشف دائنا يغفلنا عن القدرة على معرفتها، ومن ثم العجز عن علاجها، 
فالتشخيص المحايد عمل فكري من المهم ألا يسبق بمقرات تعمي عن الأداوء، ولا بعلاجات فكرية سابقة للتشخيص، فاستبعاد بعض الاحتمالات في المراحل الأولى بلا دليل يلغي البحث عنها والعلاج لها لو وجدت. فالتقديم والتأخير والتضحية ببعض الأفكار والأجزاء كأولويات الطبيب في العلاج؛ فنقبل ببتر جزء هنا أو هناك مهم، ولكن لا يصح أن نقبل بتجاهله في مرحلة الكشف عن العلة أو العلل، ونقبل أيضاً في هذه المرحلة العلاجية السكوت عن علل ناتجة أو ثانوية؛ لعدم أولويتها أو لعدم قدرتنا على التعامل معها.

\section{الميل الكلامي والسلفي والفلسفي:}

يبدو الكاتب محافظاً على مدرسة الأشعرية الكلامية إلى حد ما، يتجلى في موقفه السلفية ومن الفلاسفة ومن عدم الوضوح في تفسير التخلف ويحتاج للفلسفة المعاصرة أيما حاجة، وساعدته المدارس الفلسفية الحديثة التي رمت بقوما وراء فلسفة التاريخ، وقد غرق فيها الكاتب ردحاً من الجزء الأول، ولا شك في أنه أحسن وأجاد الفهم والنقل لكثير من النظريات. أما في الموقف من السلفية فقد وجد نفسه أسيراً لتاريخ مذهبي جغرافي في منطقته، سيطر تاريخياً وحديثاً، وإن كان هذا الفكر سيطر على الماضي فقد لا يناسب باحثاً يتجه للأمة ولنقد أفكارها وثقافتها أن يزوي نفسه في مدرسة واحدة ولا ينفتح لبقية المدارس. وهذا عائق لحرية التفكير وللحياد من المؤلف أو من المراجع. فلا نقول إن الطرفين بريئان من مهادهما المعرفي، وهذا يعين القارئ كثيراً على الاستبصار في هذه الخلافيات.

\section{دور السلفية في تحرير العقل:}

تم تغيرت الثقافة الوراثية بأسباب الصلة السياسية والفكرية بالغرب ونجاح الفكرة الإسلامية السلفية التأصيلية خارج الجزيرة، وهزيمة الطرق الصوفية، وجدت ظروف أخرى جعلت من المستبعد أن تورث الفكرة وراثة نسب، فلم يرث الكواكبي ولا سير أحمد خان ولا الأفغاني ولا عبده.

السلفية حركة تميل إلى تبسيط أمور الدين للناس، وربطهم مباشرة بالكتاب والسنة الصحيحة، فهي تجاوز للمشكلات الفلسفية، وهي بتحاوز للمعتقدات الصوفية وهي تخلص من قيود المذهبية، في عمل مفتوح للمراجعة، 
وليس إقراراً للواقع ولا قبولاً به كما هو. إنما تقف بعنف في مواجهة الخرافة سواء جاءت هذه الخرافة من قبل أوهام المتدينين، أو جاءت من قبل المنحرفين.

وظهرت هذه التبسيطية عند حسن البنا، وكان لها نفس الأثر الجماهيري للدعوة السلفية ولكن الحالة الاستعمارية التي واجهها البنا لم تسمح بنضوج ولا بتطبيق. ولا بظروف كالتي تمتعت بها السلفية من عزلة مفيدة تساندمحاضن الكيانات عند ميلادها، ثم تلبس دورها بحس عربي مؤسس-رآه هكذا القوميون العرب -، وصاغت موقفاً ضد حكم تركي مريض في المرحلة الأولى ثم وهو يلفظ أنفاسه. ثم أصيبت السلفية مبكراً بمشكلات التقليد ومشكلات السياسة والوراثة، التي أصيب بها غيرها من الحركات الأخرى.

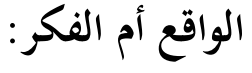

إن الجانب الاجتماعي والسياسي كان يتوارى في البحث كثيراً؛ ليأخذ مكانه الفكر، شرحاً أو مطمحاً، وهذه نزعة مهمة ومطلوبة ولعلها من الأهداف المهمة للكاتب ولكنها كثيراً ما تخلط التحليل بالأمل، فتقضي الطموحات المستقبلية على الصورة الصحيحة للماضي، ولعل من المناسب لمن يبني إيديولوجية أن يفسر الماضي حسب ما يطمح له هو في المستقبل، وهذا لسان حال الإيديولوجي دائماً، وهو سر النجاح والفشل في نفس الوقت. سر النجاح عندما ينطبق التحليل مع الواقع فيؤدي للنجاح، وسر الفشل عندما ينفصلان بصحة أحدهما أو خطأ الاثنين.

والذي أبقى مرونة، وأطال من نفس الفلسفة الغربية الرأسمالية أن التحليل الفكري والسياسي للماضي مفتوح ومتعرض دائماً للنقد والمراجعة مهما يكن، على حين المدارس الصغيرة والنهائية التي تمارس القطيعة في فلسفتها، تغادر التحليل إلى الدعاية تحت إلحاح الإيديولوجي الصارم الذي صمم مسارات ثقافية قطعية أو بمصطلحاتم حتمية، فهذه الفلسفة تلغي الواقع والتجارب العملي معله، وتحوله إلى مادة ساكنة سبق أن تم فهمها بلا مراجعة. وهذه نزعة موجودة دائماً. ولعل فكرة "هاية التاريخ" ماهي إلا نوعة لإلقاء الحتمية على الثقافة الغربية الرأسمالية.

قد لا يكون للطموح في الفصل بين التحليل والأمل فائدة؛ لأن المحلل لمجتمع أو مدرسة أو ثقافة، يحمل قبل ذلك وبعده هويته الخاصة، يرمي بها على كل الأفكار التي يعبر بها، ويحب ويكره وينقد ويزكي في أغلب مواقفه متأثراً 
هذه الحقيقة الإنسانية التي لا نماري في أثرها، وفي فائدتا، وفي سلبيتها أيضاً، ويبقى أن التحليل البعيد من المؤثرات والتحيزات هو خير وسائلنا لمعرفة الماضي والواقع، وخير وسيلة نصنع بها المستقبل. وقد حاول الكاتب الجاد وبذل جهداً مشكوراً في هذا العمل الجليل لدراسة وتوجيه التحضر الإسلامي الذي يبقى أكبر من مدرسة ومن شخص.

\section{تقويم المؤلف للمشاريع الإسلامية:}

يعرف السلفية نقلاً عن فتحي عثمان بأها "دعوة متجددة دوماً، وهي على ذلك دعوة ملائمة لعصرنا ولكل عصر؛ لأفها تربط المؤمنين بالينابيع الصافية، وتسقط عنهم رواسب القرون والأجيال من ابتداع البشر، وتعيدهم إلى كتاب الله المحكم المبين وسنة رسول الله صلى الله عليه وسلم البيضاء النقية"5 والسلفية في حركاتحا الثلاث كما يقول وضعت مضموناً ومنهجاً في معزل عن حضارة الغرب. 6

النقد على الوهابية: إذا تخلو من منزع روحاني يضيء به التوحيد جوانب النفس". والاجتهاد أصبح مقصوراً

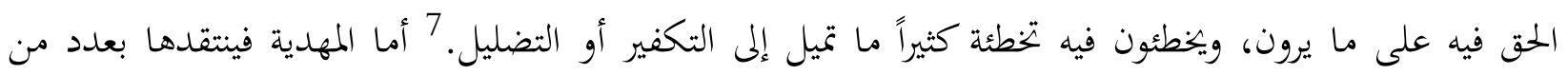

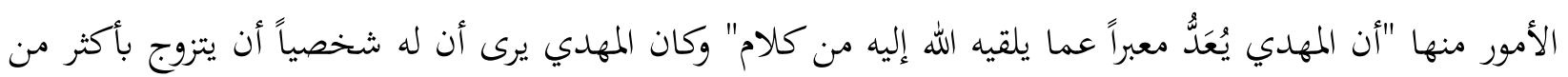

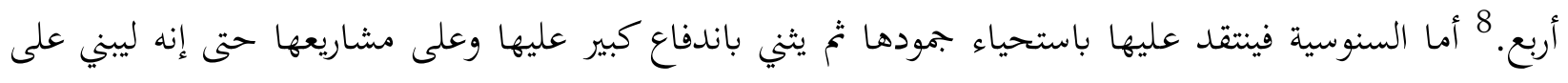
"لو" يقول: "لو كتب لتلك التجربة أن يدخلها التطور آخذاً بمكتسبات العلم الحديث لكان للسنوسية في الإصلاح والتعمير شأن آخر ذو أثر بعيد في ترقي المسلمين"9 التي لو حققوها لكانوا قاموا بأكبر مما قاموا به فمشروعهم "على درجة كبيرة من الرشد"10 ثم يقول: "وأما الحركة السنوسية فقد كان البعد الدعوي والتربوي فيها أكثر تؤدة ورصانة، بهري وأكثر عمقاً و تأثيراً، وهو ما بدا في تتابع قادة عظام عليها مثل المهدي السنوسي وأحمد الشريف"11 وهذه مبالغات

$$
\begin{aligned}
& 5 \\
& 6 \\
& 7 \\
& 8 \\
& 9 \\
& 10 \\
& 11 \text { ج } 10
\end{aligned}
$$


أنسته مسائل منها أن السنوسي ورث ابنه وطلب بيعته وألقى عليه قداسة ومهدية وجموداً قبل الإثمار. وهذا النص الذي كتبه النجار أقرب لكلام الأنصار المعجبين منه بكلام الناقد الدارس، كما بتلى في مواقف له أخرى مع مشاريع رآها بعين بصيرته لا بعاطفته.ونقده على تلبس الوهابية والمهاية بالسلطة وارتكاب المقاتل في صفوف المسلمين، 12 فما هذا إلا لأن الحركتين وصلتا إلى السلطة، ولو وصل غيرهم لفعل فعلهم، تحت شعار محاربة الشرك كالذي رفعته الوهابية، أو بحجة محاربة المهدي كالذي حدث منهم ضد خصومهم. ولم تكن السنوسية أقل استعداداً من غيرها. أما المشروع التحرري فهو مشروع قام على الصلة بالفكر والسياسة والمواجهة مع الغرب، "وهكذا كان المحور الذي تدور عليه مشاريع الإصلاح هو محور الحرية"13 ثم يعقب: "وهو المسوغ الذي جعلنا نسمي هذا المشروع بالتحرري، فمطلب الحرية يكاد يكون المطلب الذي يجتمع عليه كل من اندرج في هذا المشروع، بل هو يكاد يكون الخيط الناظم".

ولكن الحرية السياسية "لا تظفر إلا بالإشارات العابرة المتناثرة في الرسائل والمؤلفات....والخلو من برنامج علمي مفصل للحرية بمفرداته وضوابطه، بل لو تفحصنا الواقع لوجدنا جبة هذا المشروع خرج منها تياران مناقضان للتحرر أحدهما مال إلى الانفلات متمثلاً في قاسم أمين زمن شبابه، وثانيهما مال إلى الجمود ولعل من بوادره كان الشيخ محمد رشيد رضا". 15 وقد كانت دعوة الإفادة من التقدم الغربي -التي يرفعها هذا التيار- دعوة يحركها الشعور بالضعف من جهة، والافتتان بالرقي الذي عليه أوروبا من جهة أخرى، وذانك الانفعالان العاطفيان حجبا الفكر التحرري عن وضع خطة منهجية تكون على أساسها الإفادة من الغرب". 16

\begin{tabular}{|c|c|}
\hline ج3 ص73. & 12 \\
\hline ج3 ص78. & 13 \\
\hline ج3 ص100-101. & \\
\hline ج3 ص163. & \\
\hline ج3 ص167. & \\
\hline
\end{tabular}


وهذا الخط العريض المندرج تحت اسم التحرر يدمج فيه الطهطاوي الذي يقول عن الرقص في مصر "من خصوصيات النساء؛ لأنه لتهييج الشهوات، وأما في باريس فإنه نط مخصوص لا يشم منه رائحة العهر أبداً"17 ومنه لئه ابن باديس الذي لا يستقبل أو يكره أن يستقبل بعض المسلمين لأفم يلبسون البنطلونات لباس الغربيين. 18 ويعقب في وضوح أن بعض هؤلاء التوفيقيين حاولوا محاولات توفيقية فجة بين الإسلام ومظاهر الغرب، أدى ببعضهم أن يحاول تأويل القرآن بما يتناسب مع مبادئ الثورة الفرنسية. 19 ويخلص إلى نقد آخر على المشروع مثل مثاليته، والبقاء على المسلك التربوي، ثم يقول :"وإن الباحث ليعجب كيف أن المشروع السلفي توفر على ما افتقر إليه مشروع التحرر من منهجية التعبئة الشعبية، والتنظيم الحركي الواسع،

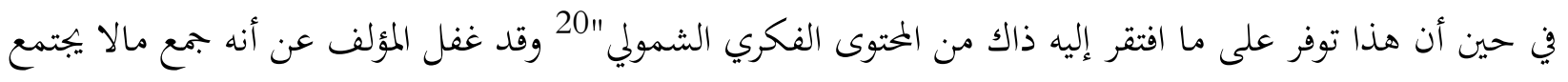
تم جعله مشروعاً واحداً متنوعاً. كال له مالا يستحق من الإعجاب.

أما مشروع الإحياء الإيماني فيعرفه البنا بقوله: "إن الإخوان المسلمين دعوة سلفية وطريقة صوفية وهيئة سياسية وجماعية رياضية ورابطة علمية ثقافية وشركة اقتصادية وفكرة اجتماعية"21 والمشروع جاء شاملاً؛ لأن الخلل كان "شاملاً فقد بلغ من الشدة مالا يمكن أن يحركه إلا إحياء إيماني شامل". 22

ويرى في المشروع الإيماني مشروع البنا والمودودي، مشروعاً أكمل من سوابقه في جوانب وأقل نضوجاً في جوانب التأصيل -عدا شخص المودودي- ولكن حركته مقلدة. ويغفل الكاتب لسبب ما أثر المودودي على مشروع الإحياء الإيماني، وهو يناقش القضايا والمفاهيم التي أثارها سيد قطب، وهي حقاً من أثر المودودي عليه. وليس من داخل مدرسته؛ إذ برز التأصيل العلمي للمودودي أكثر من غيره في هذه المدرسة، وهو الذي كتب التفسير والسيرة وكتب كثيراً في الفقه السياسي.

$$
\begin{aligned}
& 17 \\
& 18 \\
& 19 \\
& 20 \\
& 21 \\
& 22
\end{aligned}
$$


ويلاحظ على مدرسة البنا خاصة: "منزع الإجمال في وصف الواقع... وبحث هذه المدرسة عن أسباب تخلف المسلمين كان ضعيفاً وسطحياً"23 وكان هناك ميول روحانية ومخاطبة العاطفة أقوى منه مخاطبة العقل، واستنهاض الروح فيها أقوى من استنهاض الفكر، وتتجه إلى تربية الن فوس بأقوى مما تتجه إلى تربية العقول، ومن الواجبات اليومية المنتسب إلى حركة الإخوان قراءة مأثورات ذات أثثر روحاني، ولكن ليس من بينها قراءة تفسير قرآني". 24 ومن المميزات لحركة البنا شعبيتها ف "الخلية الأولى التي كون منها حسن البنا حركة الإخوان المسلمين تضم ستة نفر هم: نجار وحلاق وكواء وبستاني ومصلح دراجات وسائق" "25 وقد كان لهذا أثره على المسألة الفكرية.

وينتقد على مشروع المودودي أيضاً أنه كان بجملاً ولم يفصل ويفاضل فيما بينه وبين مشروع الرفاه في تركيا،

وسبب فوزه وعدم فوز الجماعة في باكستان أن الرفاه كان له برنامج مفصل، ومشروع الجماعة الإسلامية عاماً. 26 ويخلص إلى القول: "إن الأمة الإسلامية لم تحدث فيها إلى الآن هضة ولا حتى إرهاصات فضة بالمعنى الحقيقي، ودع عنك ما تراه من مظاهر التمدن التي تتوافر هنا وهناك في مدن العالم الإسلامي، فإنها مظاهر تكديس لسلع مستجلبة".

ويدعو الكاتب إلى المبادرة "فالتاريخ لا تصنعه التلقائية الآلية، ولكن تصنعه الإرادة الإنسانية". 28 ويدعة للمعرفة، والرسوخ في العلم. "وحركات الإصلاح عموماً حينما لا تكون مدعومة بحركة علمية تأصيلية واسعة فإنها تكون خفيفة الواقع".

خلاصة:

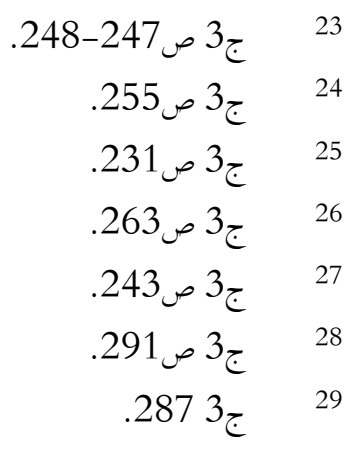


يتضمن الكتاب نفسه أكثر من بذور مشروع للنهوض الإسلامي، ولولا بعض المهاد الثقافي الذي قيد الكاتب من حرية المواجهة المعتدلة أحياناً لكان أنموذجاً للنقد الإسلامي للفكر الإسلامي ومدارسه، ولكانت كثير من قضايا الكتاب أوراق غوض مهمة. وفي الكتاب نضوج في النقد يندر عند غير النجار، وهو غالباً صريح، فلم يمنعه كون كتابه جزءاً من مشروع معهد الفكر أن ينبه بقوله: "فإن هذا المشروع الجدديد الذي هو بصدد التشكيل متخذاً من إصلاح الفكر محوراً أساسياً له، يخشى بحسب بوادر أوليه تبدو عليه أن يكون مشروعاً مخلاً هو أيضاً بعوامل أخرى من عوامل التحضر، وعلى رأسها عامل النفير العام الذي يستنهض أعماق الأمة في أبعاد المقدرات الفردية.... فهذه البوادر تشير إلى منزع يميل إلى النخبوية الضيقة، والانعزالية عن التيار الكبير للوجود الشعبي الإسلامي. فالشعوب هي التي تضع الحضارة وليست النخب". 30

سيبقى جهد الدكتور النجار في هذا الكتاب معلماً في رصد الفكر الإسلامي وتوجهاته، وعنايته بالتنظير للمستقبل موضع تقدير من يأتي بعده، أو يبحث عن نماذج في الفكر الإسلامي حاولت التنظير للمستقبل الإسلامي. 